\title{
Design and Characterization of Ultra-Wideband Horn Antenna in Quasi-TEM Mode
}

\author{
Evandro C. V. Boas, Jéssica A. P. Ribeiro, Karine L. M. Costa, José A. J. Ribeiro, \\ Antônio M. Alberti and Arismar C. Sodré Jr.
}

\begin{abstract}
This paper describes the ultra-wideband horn antenna design operating in quasi TEM mode. The antenna consists of a triangular plate with an inclination angle above a ground plane and directly fed by a coaxial cable. Broadband characteristics, radiation pattern, high gain, and a small reflection coefficient were achieved. Its performance analysis and main parameters effects were obtained by using ANSYS HFSS ${ }^{\circledR}$ software. In the numerical analysis, an optimized model was obtained in 1.57 to $12.85 \mathrm{GHz}$ bandwidth an 11 to $14 \mathrm{dBi}$ gain. The proposed antenna was manufactured and the measured reflection coefficient results show an operation frequency range between 1.48 and $10.12 \mathrm{GHz}$, agreeing very well with simulations.
\end{abstract}

Keywords-Horn antenna, Quasi TEM mode, Wideband.

\section{INTRODUCTION}

W IDEBAND structures have been employed in different radio communication systems. As example, ultrawideband radio communications systems (UWB) operating in $1 \mathrm{GHz}$ to $10.6 \mathrm{GHz}$ frequency band are applied in ground penetration radars (GPRs) [2], wall imaging systems [3], surveillance systems [4], among others [5]. With the wireless technology advancement, radiator operations in $2.45 \mathrm{GHz}$ and $5.8 \mathrm{GHz}$ industrial, scientific and medical (ISM) bands are highly applied. There are also demands on spectral sensing systems, in 5G technologies, in more efficient cognitive radio systems, and so one [6], [7]. Such systems must satisfy broadband frequency specifications. These systems must ensure minimal mutual interference in transmission channels. Transverse electromagnetic wave (TEM) mode is typical in unlimited environments propagation. To avoid signal dispersion, the attenuation factor must be frequency independent and the phase factor must be linearly frequency dependent [8]. A low-loss transmission line approximately presents these conditions. In this way, its characteristic impedance turns

Evandro C. V. Boas, Jéssica A. P. Ribeiro, Karine L. M. Costa, José A. J. Ribeiro, Antônio M. Alberti and Arismar C. Sodré Jr. are with National Institute of Telecommunications (Instituto Nacional de Telecomunicações - Inatel), João de Camargo Avenue 510 P.O. Box 05, 37540000, Santa Rita do Sapucaí, MG, Brazil. (e-mails: evandro.cesar@inatel.br, jessica.ribeiro@mtel.inatel.br, karine.costa@mtel.inatel.br, justino@inatel.br, alberti@inatel.br, arismar@inatel.br).

Evandro C. V. Boas and Arismar C. Sodré Jr. are with WOCA (Wireless and Optical Convergent Access) Laboratory. Karine L. M. Costa and Antônio M. Alberti are with ICT Lab (Information and Communication Technologies Laboratory)

A preliminary version of this paper was presented in XXXV Simpósio Brasileiro de Telecomunicações (SBrT'17), São Pedro, SP, Brazil, September 3-6, 2017 [1].

Digital Object Identifier: 10.14209/jcis.2018.34 an almost real value and the same impedance load makes its operating range very high. In this context, some antenna models, such as the TEM horn antenna, have been developed with a compromise between a transmission line and radiation phenomenon behaviors. According to their geometries and design procedures, reflections in their extremities are avoided. These antennas assume an almost ideal transmission line operation with a wide bandwidth because the radiated power has a load effect close to its characteristic impedance [9].

The basic TEM horn antenna, composed of two triangular metal plates and a feeding structure, has been widely studied in the last years. Some researchers proposed analytical solutions to evaluate its characteristic impedance in terms of its constructive parameters. In 1958, Carrel [10] presented a theoretical method by applying the conformal mapping approach in calculating the characteristic impedance of two infinite cones. This method might be extended to the analysis of inclined biconical antennas or similar structure, as the TEM horn antenna. After, Yang and Lee [11] combined two techniques, stereographic projection, and conformal mapping, in the calculation of two conical plates characteristic impedance. In 1995, Lambert et al. [12] proposed a new formulation also based on the conformal mapping approach to turn Carrels method more accurate. In that same year, Maloney and Smith [13] proved that the characteristic impedance obtained by Carrels method only matched with measurements for the bowtie antenna case. In 1996, Shlager et al. [14] formulated an analytical solution for the characteristic impedance in a TEM horn antenna by considering the triangular metal plates as a cascade of microstrip line segments. Lately, Lee and Smith [15] compared the aforementioned analytical formulas with a numerical solution. The results agree with the Maloney and Smith conclusion about Carrels method. The formulas proposed by Yang and Lee and Lambert et al. confirm the numerical solutions and the Shlager et al. approach has a good agreement only for small aperture between the triangular metal plates.

Other researches related to TEM horn antenna have been focused on a design modification to improve the performance. Theodorou et al. [16] analyzed the characteristics of the TEM horn antenna by derivation from a V-shaped dipole antenna. Lee and Smith [17] presented a study about the effects of the main constructive parameters on the TEM horn antenna as input impedance, bandwidth, gain, and radiation pattern. Baker and Van Der Neut [18] proposed a TEM ridged horn antenna composed by a combination of double ridge waveguide with a cylindrical termination and microwave absorbing material. 
This structure is presented as a solution to reduce the size of a broadband double ridge pyramidal horn antenna. In subsequent works, the double ridge waveguide properties were used to design TEM horn antennas with improved bandwidth [19] as well as the idea of loading the antenna with an absorbing material [20]. In fact, loading the antenna with a microwave absorbing material reduces reflections at lower frequencies, increasing the bandwidth as a result. An alternative technique to mitigate reflections at lower frequencies and to increase the bandwidth is loading the TEM horn antenna resistively. It was introduced by Kanda [21] and explored in other works [22], [23]. However, both resistive and absorbing loading techniques have as the main disadvantage to increase the antenna losses, causing a reduction in the antenna gain. This drawback has motivated researchers to propose techniques to improve the TEM horn bandwidth without degrading other performance parameters. By that, modification in the TEM horn crosssection profile has been proposed as exponential [24], [25], [26], [27], and elliptical profiles [28].

The previously related researches show structure modification in order to improve performance, mainly increasing the antenna bandwidth at lower frequencies. However, the object is not to propose a design method, numerical evaluation and prototype characterization of a TEM horn antenna as in this paper. It discusses a design procedure by establishing a relationship between the antenna dimensions and the lowest operation frequency. The microstrip model approach proposed by Shlager et al. [14] was applied in the aperture dimensions of the triangular metal plate determination.

In this way, a horn antenna with a field distribution close to TEM wave in a transmission line is designed. Their dimensions were chosen above $1.5 \mathrm{GHz}$ and its development is presented in six sections. In Section II, the antenna basic models and their characteristics are presented. Section III refers to a design method by assuming the quasi-TEM mode operation, i.e., with field longitudinal components very small compared to the transverse ones. To obtain its dimensions, the model proposed by Shlager et al. [14] is applied. The performance of the initial structure is verified by numerical analysis with ANSYS HFSS ${ }^{\circledR}$ software [29]. SMA connector with its constructive characteristics (material, dimensions) was specified to obtain the antenna dimensions. This step is in Section IV, where the constructive parameters effects on the antenna performance are evaluated. An optimized model and its reflection coefficient, input impedance, radiation pattern, and gain are obtained. Section $\mathrm{V}$ presents the prototype after different development essays. Its frequency response was evaluated through the reflection coefficient measurements and the results compared with the numerical analysis. Section VI discusses the project important results and relevant conclusions.

\section{BASIC QUASI-TEM HORN ANTENNA}

The radiation transmission line behavior capacity is used to design the proposed wideband horn antenna. A null reflection coefficient is obtained with an infinite length or finite structure with an impedance load equal to its characteristic impedance (matched line). In radiation structures with low reflected energy, the performance is similar to a matched line that has a very high bandwidth.

The proposed antenna model begins with a balanced composition of two triangular metal plates with an angular separation. This structure demands a feed system adaptation to the unbalanced coaxial cable [17], [23]. Its dimensions and separations were gradually modified to obtain the desired performance. As there is no abrupt transition between the guided wave and the external environment, small reflection results at its end. The antenna design depends on three variables: the electrodes angular aperture $\alpha$, their angular separation $\beta$ and the axial length $\ell$ from the driven point to electrodes end (Fig. 1).

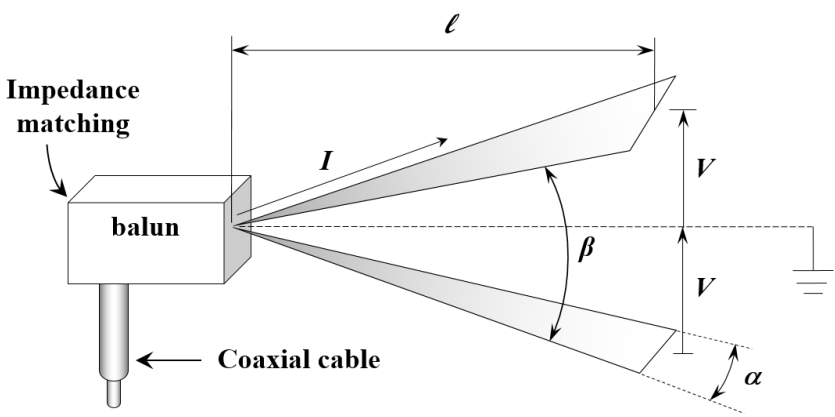

Fig. 1. Symmetric structure of the horn antenna operating in quasi-TEM mode, fed through a balun.

In the guided wave antenna section, the electric and magnetic fields are almost perpendicular to each other and transverse to the propagation direction, in a quasi-TEM behavior. The electric field must always be perpendicular to the gradually separated conducting surfaces. In order to satisfy the boundary conditions, the electric and magnetic fields assume mutually perpendicular directions, as in Fig. 2 scheme. For that, a characteristic impedance may be defined for this structure [30] and the input impedance coincides with its characteristic impedance if there are no reflections. This implies in the total radiation of the guided energy. In the described antenna, if the transition is soft enough so that most of the energy is transferred to the external medium, its behavior is similar to a matched structure and the input impedance will have a significant contribution of its characteristic impedance.

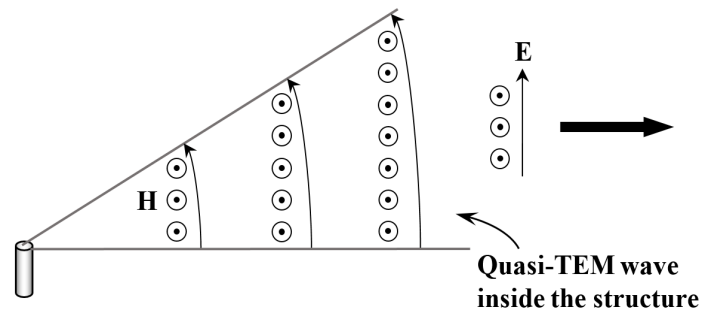

Fig. 2. Quasi-TEM wave formation schematic representation in the analyzed structure.

The antenna in Fig. 1 is a balanced structure usually excited by a $50 \Omega$ coaxial cable, an unbalanced transmission line. For that, the radiation and matching characteristics demand an adaptation element between symmetrical and asymmetric 
systems (balun). Its objectives must fulfill in the whole specified antenna bandwidth. This is not an easy task since the antenna characteristics and of the adapter itself change with frequency. In Fig. 1, there is a hypothetical reference plane between the conductor plates. There is a voltage $V$ between an antenna branch and the reference plane and another identical voltage between this plane and the second antenna electrode. The electric current $I$ is the same at both driven points. In this way, the input impedance is [17]:

$$
Z_{1}=\frac{2 V}{I}
$$

Fig. 3 shows a modification in original structure with one conductor forming a ground plane at the reference plane position. This new version is an unbalanced structure more convenient to a coaxial cable [31]. The applied voltage is half the previous value for the same driven point current. The input impedance is half of the obtained in (1):

$$
Z_{2}=\frac{V}{I}
$$

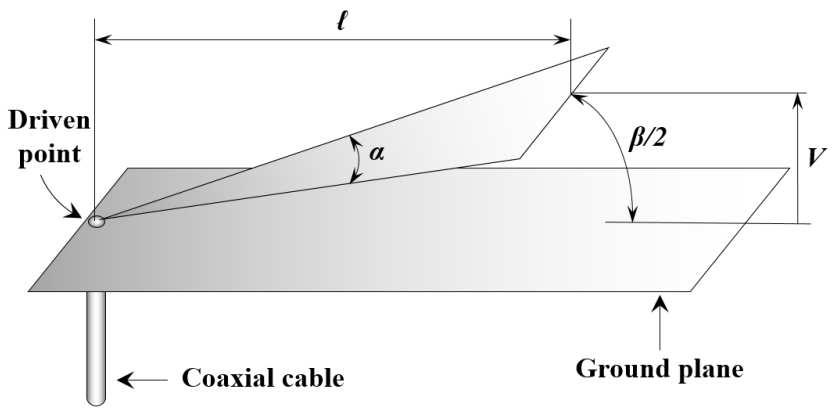

Fig. 3. Asymmetric structure of the horn antenna operating in quasi-TEM mode. Its an unbalanced structure, directly fed.

\section{ANTENNA DESIGN}

The structures in Fig. 1 and Fig. 3 have the same constructive parameters $\alpha, \beta$ and $\ell$. Thus, the design procedure is identical, except for particular characteristics of each structure. In Fig. 1, the characteristic impedance, $Z_{c}$, is twice the desired value in Fig. 3. This structure follows the description if its axial length is equal to or greater than 1.3 times the guided wavelength at the lowest operation frequency [1]:

$$
\ell=1.3 \lambda_{\max }=\frac{1.3 c}{f_{\min }}
$$

with $f_{\min }$ the lowest operating frequency and $c$ the speed of electromagnetic wave in vacuum.

To calculate $\alpha$ and $\beta$ there are some analytical models with very good results [12]-[15]. The microstrip model approach, proposed by Shlager et al. [14], is suitable for $\alpha$ and $\beta$ between $0^{\circ}$ and $60^{\circ}$ [15]. By considering this model, the antenna behavior is close to a cascade of microstrip line segments. In this transmission system, the characteristic impedance depends on strip width $(w)$ and the thickness of the dielectric layer between the metal strip and the ground plane $(h)$. These dimensions in Fig. 4(a) and Fig. 4(b) represent the extension of the triangular plate base and the height with respect to the ground plane.

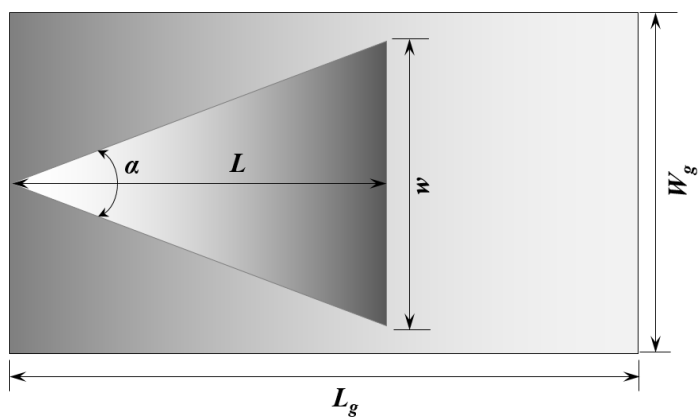

(a)

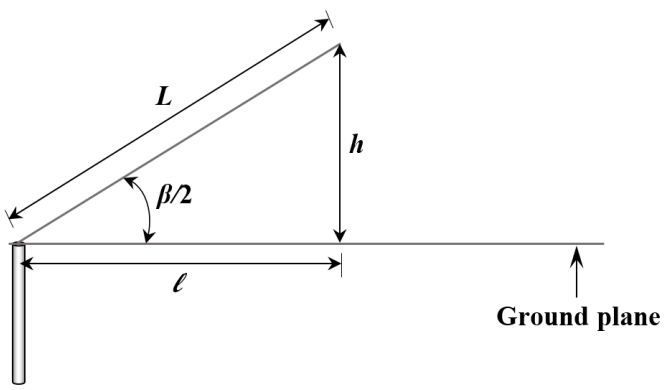

(b)

Fig. 4. Geometry of proposed asymmetric quasi-TEM horn antenna. (a) Upper view and (b) side view.

Through trigonometric relations its possible to obtain $\alpha$ as a function of $\beta$ and the ratio $w / h$ :

$$
\alpha=2 \operatorname{atan}\left(\frac{w}{2 h} \sin \left(\frac{\beta}{2}\right)\right)
$$

As proposed by Shlager et al. [14], the relationships between geometric parameters and characteristic impedance are:

$$
\begin{gathered}
A=\frac{\pi Z_{c}}{\eta_{o}} \\
\frac{w}{h}=\frac{8}{e^{A}-2 e^{-A}}, \quad \text { to } \quad \frac{w}{h}<2 \\
\frac{w}{h}=\frac{2}{\pi}\left[\frac{\pi^{2}}{A}-1-\ln \left(\frac{2 \pi^{2}}{A}-1\right)\right], \quad \text { to } \quad \frac{w}{h} \geq 2
\end{gathered}
$$

where $\eta_{o}$ represents the medium intrinsic impedance, in general, the air, where $\eta_{o}=377 \Omega$. By assuming different values for the characteristic impedance, applying (4) and considering values between 0 and $60^{\circ}$, it was established a relationship between $\alpha, \beta$ and $Z_{c}$, as in Fig. 5. As the antenna characteristic impedance increases, the aperture of the triangular metal plate reduces and the aperture between the antenna branches increases.

The transmission line approach defines some free variables: $Z_{c}$ and one of the angles $\alpha$ or $\beta$. In this work, $\beta$ was chosen as the free variable. Once the parameters $\alpha, \beta$ and $\ell$ have been defined, the length $L$ and the aperture $w$ of metallic triangular plate are obtained by:

$$
L=\ell \sec \left(\frac{\beta}{2}\right)
$$




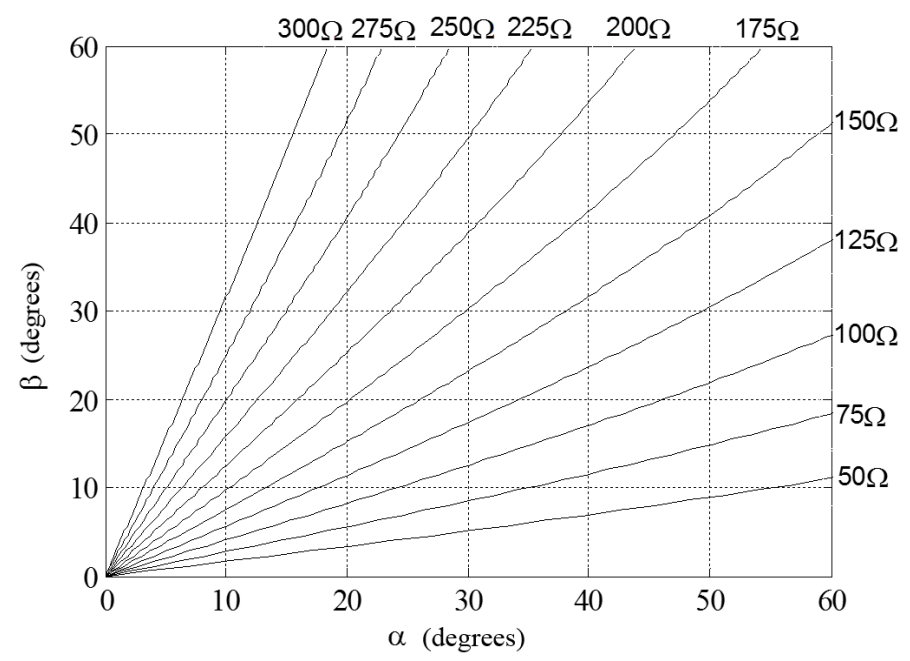

Fig. 5. $\alpha$ and $\beta$ for different values of the characteristic impedance of the horn antenna operating in quasi-TEM mode, using the transmission line approximation model.

$$
w=2 \ell \sec \left(\frac{\beta}{2}\right) \tan \left(\frac{\alpha}{2}\right)
$$

\section{HORN ANTENNA ANALYSIS IN QUASI-TEM MODE OPERATION}

\section{A. Antenna geometric values}

Section III presented the design of the horn antenna in quasi-TEM mode with an unbalanced fed. There are small differences among theoretical and real parameters because of manufacturing process tolerances. The antenna structure will be fed with a $50 \Omega$ coaxial cable. Therefore, the balanced model was designed with $100 \Omega$ characteristic impedance providing matching condition between the driven point and the radiation element. The minimum specified frequency is 1.5 $\mathrm{GHz}$ and $\beta=20^{\circ}$. By applying transmission line approach [14], under the condition where $w / h \geq 2$ the $\alpha$ value is $46^{\circ}$. Table I exhibits the triangular plate and ground plane dimensions values. The antenna performance was evaluated through the Finite Element Method (FEM) with ANSYS HFSS ${ }^{\circledR}$ software [29]. The prototype specified conductor material is aluminum and the numerical model was analyzed by employing its properties.

TABLE I

DESIGN PARAMETERS TO THE QUASI-TEM HORN ANTENNA.

\begin{tabular}{|c|c|}
\hline Parameter & Value \\
\hline$Z_{c}$ & $50 \Omega$ \\
\hline$\alpha$ & $46^{\circ}$ \\
\hline$\beta$ & $20^{\circ}$ \\
\hline$\ell$ & $260 \mathrm{~mm}$ \\
\hline$L$ & $264 \mathrm{~mm}$ \\
\hline$w$ & $225 \mathrm{~mm}$ \\
\hline$L_{g}$ & $400 \mathrm{~mm}$ \\
\hline$W_{g}$ & $250 \mathrm{~mm}$ \\
\hline
\end{tabular}

\section{B. Parametric values}

The effects of the main constructive parameters $\alpha, \beta$ and the ground dimensions will be evaluated. The axial length $\ell$ and the triangular plate dimensions change the lowest operating frequency as shown in (3). Likewise, the reflection coefficient was used to evaluate the antenna performance under the mentioned parameters variations.

Antenna bandwidth was limited to a reflection coefficient lower than $10 \mathrm{~dB}$. Fig. 6 shows the reflection coefficient of the initial numerical unbalanced antenna model (solid black curve). The operation frequency bandwidth is about $11.3 \mathrm{GHz}$, with lower and upper limits in $1.57 \mathrm{GHz}$ and $12.85 \mathrm{GHz}$, about $150 \%$ around the center frequency.

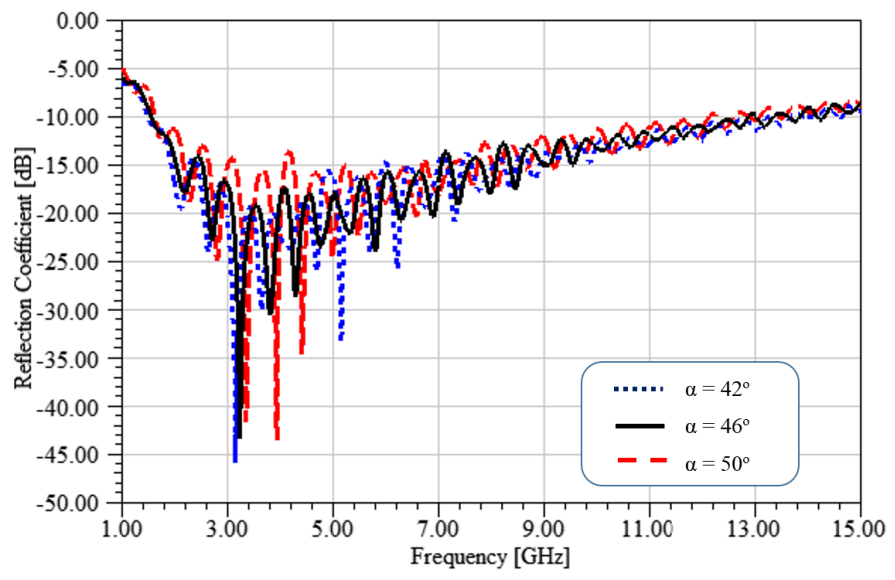

Fig. 6. Reflection coefficient, in $\mathrm{dB}$, for the directly fed quasi-TEM horn antenna, to different values of $\alpha$.

The $\alpha$ angle is the triangular plate aperture, as depicted in Fig. 4. With its values equals to $42^{\circ}, 46^{\circ}$ and $50^{\circ}$, the obtained $S_{11}$ are shown in Fig. 6. It is observed that over an $8^{\circ}$ in the $\alpha$ parameter variation there is no significant behavior changes.

The $\beta$ angle between the triangular plate and the ground plane assumes $10^{\circ}, 20^{\circ}$ and $30^{\circ}$ values in this analysis and the correspondent $S_{11}$ values are depicted in Fig. 7. The decreasing of $\beta$ changes the antenna frequency response, by reducing its bandwidth with the $S_{11}$ degradation. As $\beta$ is increased, there is also an antenna frequency response modification in terms of $S_{11}$ level, mainly in lower frequencies, but the bandwidth is preserved. The results show that the antenna impedance changes expressively for $\beta$ lower than the defined in the antenna design. However, to greater $\beta$ values the antenna impedance presents a small modification.

The ground plane length, $L_{g}$, assumed the values 300,400 and $500 \mathrm{~mm}$ and its width, $W_{g}$, the values 250, 300 and $350 \mathrm{~mm}$. The antenna frequency response (Fig. 8) shows that these parameters do not have considerable effects on its performance.

\section{Antenna Performance}

The parameters effects evaluation allowed to understand the antenna behavior under their variations. Once there was no antenna performance improvement, the final model has the same dimensions in Table I, with the frequency response of Fig. 6 (solid black curve). To characterize the final model, input impedance, gain and radiation pattern were verified in the numerical analysis. The input impedance is shown in Fig. 9, 


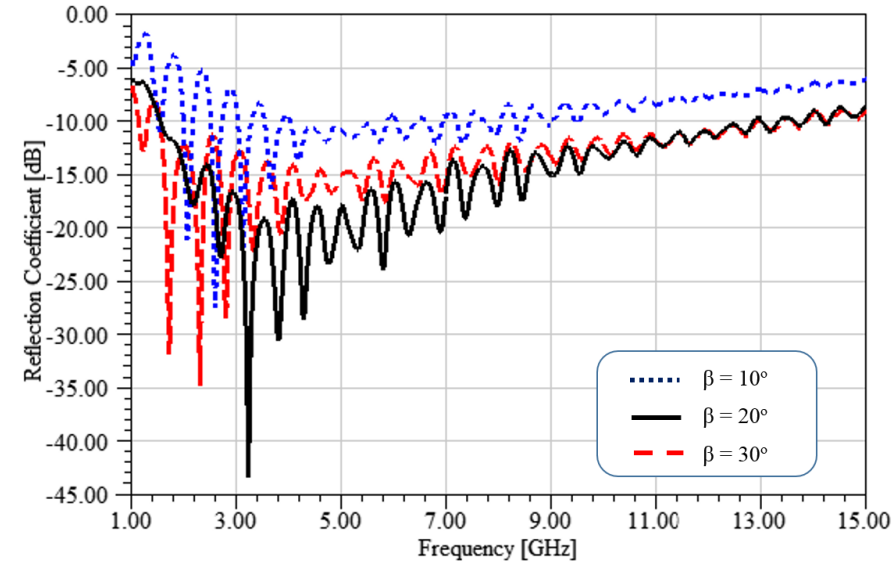

Fig. 7. Reflection coefficient, in $\mathrm{dB}$, for the directly fed quasi-TEM horn antenna, to different values of $\beta$.

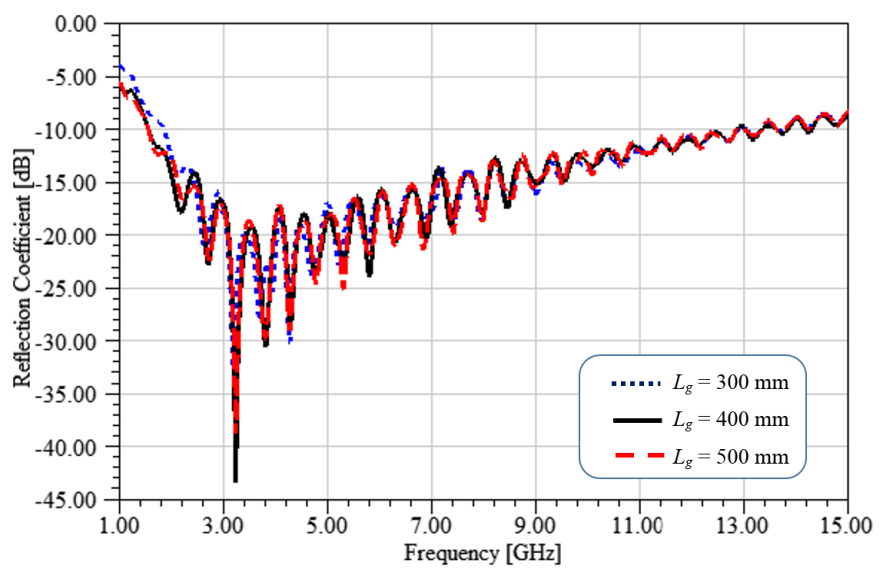

(a)

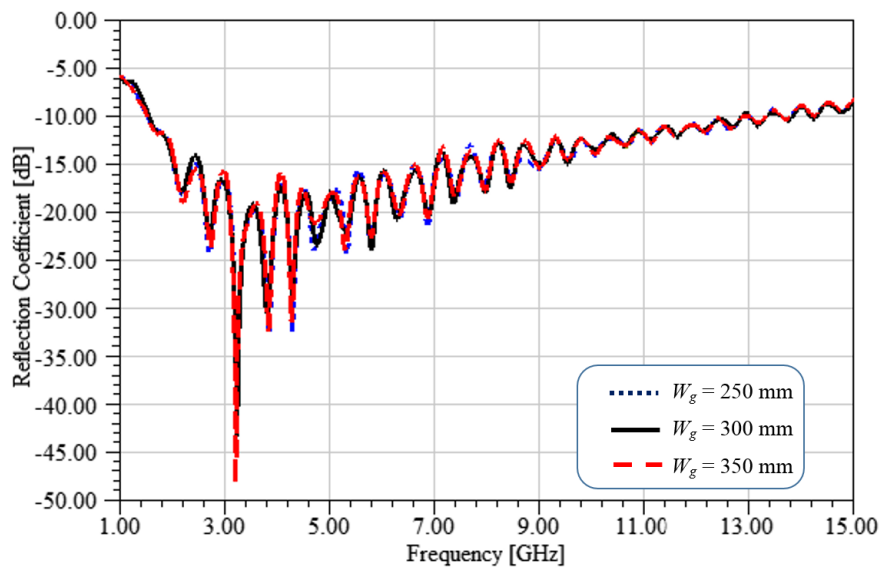

(b)

Fig. 8. Reflection coefficient, in $\mathrm{dB}$, for the directly fed quasi-TEM horn antenna, to different values of (a) $L_{g}$ and (b) $W_{g}$.

with the real part between 25 and $75 \Omega$ and the reactive part values from $-j 25$ to $j 25 \Omega$.

The gain analysis shows a variation between 11 and $14 \mathrm{dBi}$, in the frequency range, as depicted in Fig. 10. The radiation pattern is in Fig. 11 in 1.57, 7.2 and $12.85 \mathrm{GHz}$, respectively the lowest, center and higher values in frequency bandwidth. In lower frequency, the radiation pattern shows a maximum in

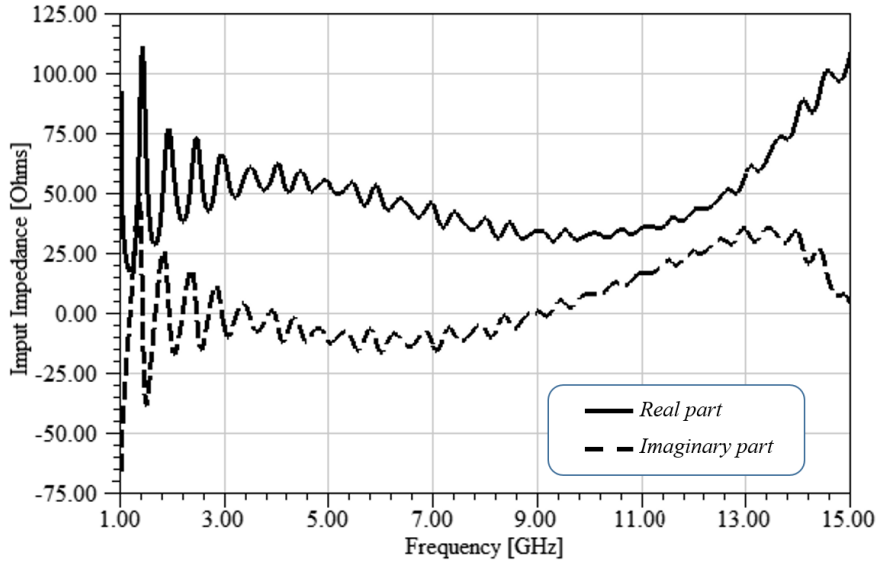

Fig. 9. Input impedance, in $\Omega$, for the designed directly fed quasi-TEM horn antenna.

a region for between 0 and $90^{\circ}$. As the frequency increases, the radiation maximum goes to the azimuthal plane direction, parallel to the antenna ground plane.

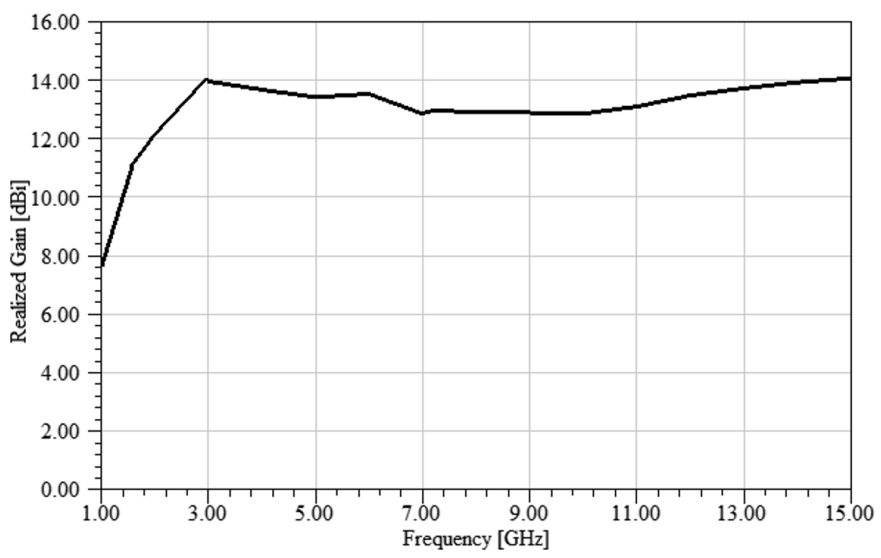

Fig. 10. Designed quasi-TEM horn antenna gain, in $\mathrm{dBi}$, over its frequency range.

\section{Measurements And Discussions}

The antenna prototype (Fig. 12) was manufactured with aluminum plates and polyvinyl chloride (PVC) supports. The electrical contact of the triangular plate and the probe needed a piece of copper laminate because the aluminum material does not allow the welding to the probe. Its use contributes to a small change in the antenna resistance, once its conductivity is greater than the aluminum, without significant modification in the antenna overall performance.

In Fig. 13, the measured and simulated results of $S_{11}$ parameter are compared. The practical results show antenna bandwidth of $8.64 \mathrm{GHz}$, between 1.48 and $10.12 \mathrm{GHz}$. It was observed differences about $5.7 \%$ reduction in the minimum operating frequency and a $23.40 \%$ in the overall antenna bandwidth. At the upper part of frequency bandwidth, measured results were better than simulated because of the power loss in SMA connector, whose performance decreases at high frequencies. By that, the reflected power decreases, resulting in a better impedance match at the driving point. 

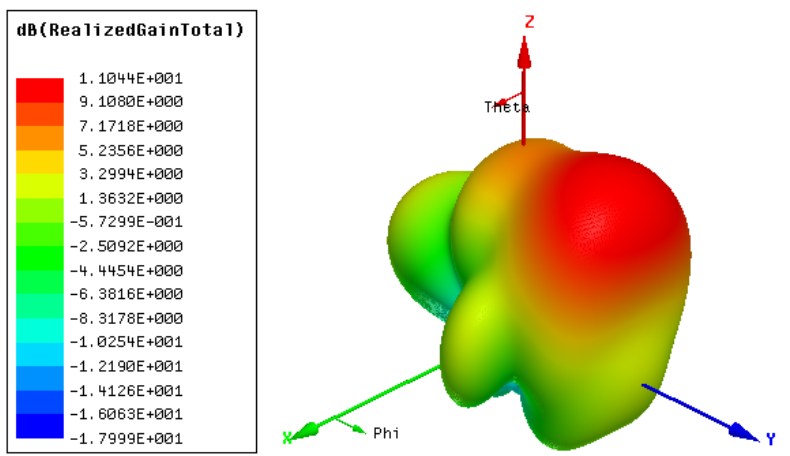

(a)
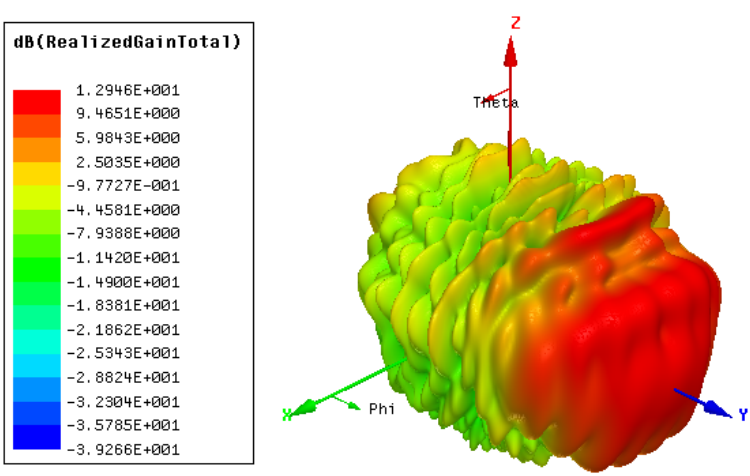

(b)
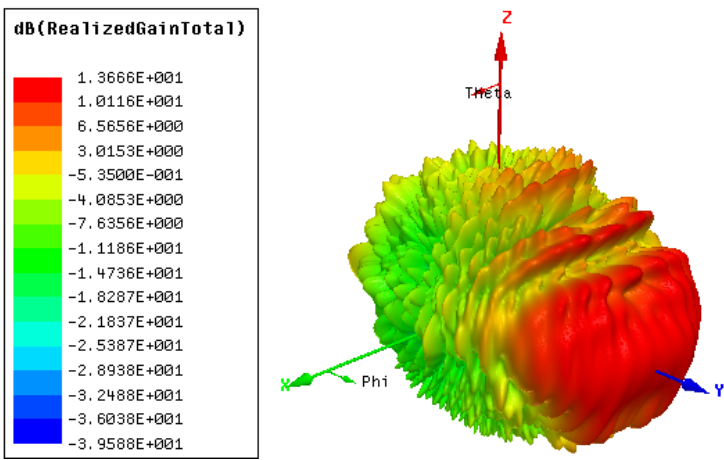

(c)

Fig. 11. Radiation pattern of the directly fed horn antenna operating in quasi-TEM mode in the operation frequencies: (a) $1.57 \mathrm{GHz}$ (b) $7.2 \mathrm{GHz}$ and (c) $12.85 \mathrm{GHz}$.

\section{CONCLUSION}

A horn antenna in quasi-TEM operation mode was proposed for wideband frequency applications. This antenna exhibits simple structure, with a combination of two conductor plates, a triangular and a rectangular. Because the unbalanced construction it is suitable to a coaxial cable fed. The microstrip approach model was employed to obtain the antenna dimensions. An optimized structure was designed by applying numerical analyses, considering SMA connector characteristics: $1.25 \mathrm{~mm}$ diameter gold plated beryllium copper probe and $4 \mathrm{~mm}$ diameter polytetrafluoroethylene (PTFE) dielectric coat. Measured results are similar to the previously obtained with numerical analysis and are in good agreement with expected characteristics and performance parameters. Compared to previous works, this model presents low loss and high gain in operation band.

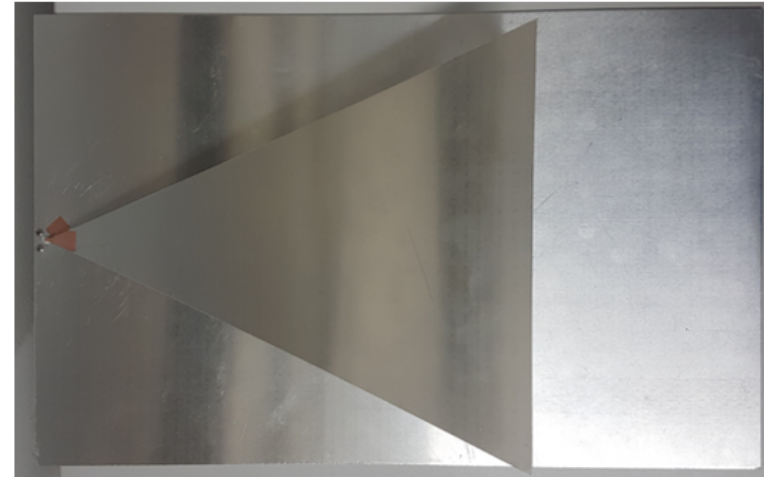

(a)

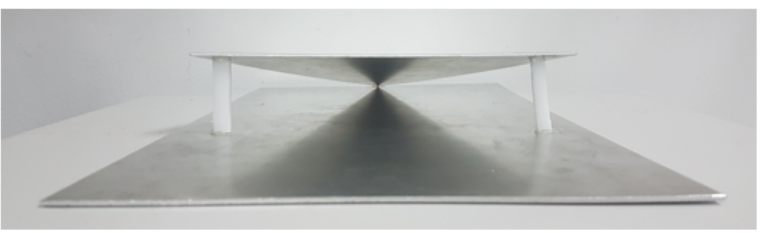

(b)

Fig. 12. Prototype of the proposed quasi-TEM horn antenna in (a) top view and (b) front view.

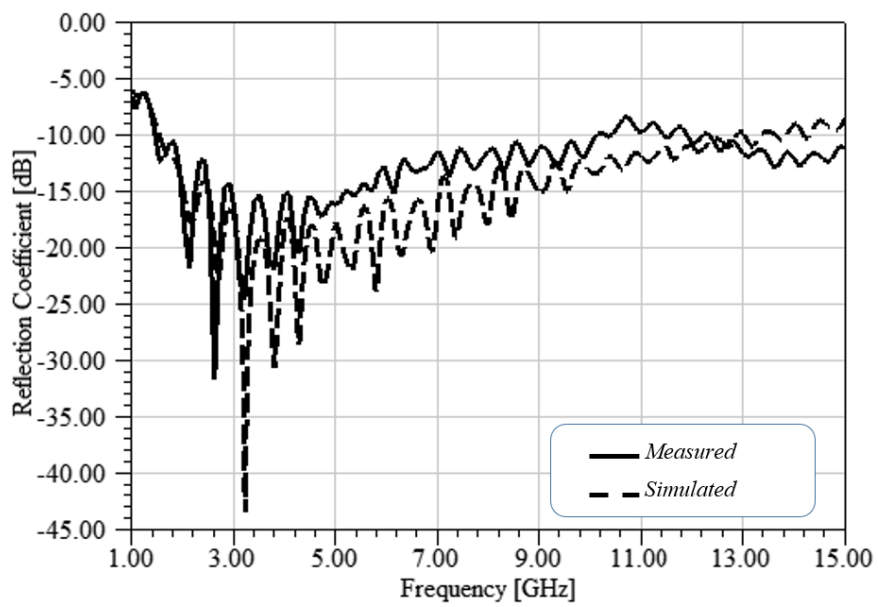

Fig. 13. Simulated and Measured reflection coefficient, in $\mathrm{dB}$, of the designed antenna.

In addition, it is a simple structure compared to other large bandwidth models, like exponential and elliptical formats.

\section{ACKNOWLEDGMENT}

This work was partially supported by Finep/Funttel Grant No. 01.14.0231.00, under the Radio Communications Reference Center project. Authors also thank the financial support from FINEP, CNPq, CAPES, MCTI and FAPEMIG and technical support from ANSYS-ESSS and Keysight.

\section{REFERENCES}

[1] J. A. P. Ribeiro, K. L. M. Costa, E. C. V. Boas, J. A. J. Ribeiro, B. R. Faria, and L. E. Adami, "Design and characterization of wideband horn antenna in quasi-TEM mode," Simpósio Brasileiro de Telecomunicações - SBrT'17, 2017. 
[2] Q. Liu, X. Cui, X. Liu, J. Chen, X. Chen, and X. Cao, "Detection of root orientation using ground-penetrating radar," IEEE Transactions on Geoscience and Remote Sensing, vol. 56, no. 1, pp. 93-104, Jan 2018. DOI: $10.1109 /$ TGRS.2017.2737003.

[3] J. Peabody Jr, G. L. Charvat, J. Goodwin, and M. Tobias, "Throughwall imaging radar," Massachusetts Institute of Technology-Lincoln Laboratory Lexington United States, Tech. Rep., 2012.

[4] F. Hessar and S. Roy, "Spectrum sharing between a surveillance radar and secondary wi-fi networks," IEEE Transactions on Aerospace and Electronic Systems, vol. 52, no. 3, pp. 1434-1448, June 2016. DOI: 10.1109/TAES.2016.150114.

[5] F. C. Commission et al., "Revision of part 15 of the communications rules regarding Ultra-Wideband (UWB) transmission systems," pp. 98 153,2002

[6] Americas, "5G spectrum recommendations," Apr. 2017. [Online]. Available: www.5gamericas.org/files/9114/9324/1786/5GA_5G_ Spectrum_Recommendations_2017_FINAL.pdf

[7] A. Ali and W. Hamouda, "Advances on spectrum sensing for cognitive radio networks: Theory and applications," IEEE Communications Surveys Tutorials, vol. 19, no. 2, pp. 1277-1304, Secondquarter 2017. DOI: 10.1109/COMST.2016.2631080.

[8] J. A. J. Ribeiro, Propagação das ondas eletromagnéticas: princípios e aplicações. São Paulo: Érica, 2004.

[9] R. C. Johnson and H. Jasik, Antenna engineering handbook - 2nd edition. New York: McGraw-Hill Book Company, 1984.

[10] R. Carrel, "The characteristic impedance of two infinite cones of arbitrary cross section," IEEE Transactions on Antennas and Propagation, vol. 6, pp. 197-201, Apr 1958. DOI: 10.1109/TAP.1958.1144578.

[11] F. C. Yang and K. H. Lee, "Impedance of two-conical-plate transmission line," The Dikewood Corporation, Los Angeles, California, Tech. Rep., 1976.

[12] A. P. Lambert, S. M. Booker, and P. D. Smith, "Calculation of the characteristic impedance of TEM horn antennas using the conformal mapping approach," IEEE Transactions on Antennas and Propagation, vol. 43, no. 1, pp. 47-53, Jan 1995. DOI: 10.1109/8.366350.

[13] J. G. Maloney and G. S. Smith, "On the characteristic impedance of TEM horn antennas," in IEEE Antennas and Propagation Society International Symposium. 1995 Digest, vol. 1, June 1995, pp. 182-185. DOI: 10.1109/APS.1995.529991.

[14] K. L. Shlager, G. S. Smith, and J. G. Maloney, "Accurate analysis of TEM horn antennas for pulse radiation," IEEE Transactions on Electromagnetic Compatibility, vol. 38, no. 3, pp. 414-423, Aug 1996. DOI: $10.1109 / 15.536071$

[15] R. T. Lee and G. S. Smith, "On the characteristic impedance of the TEM horn antenna," IEEE Transactions on Antennas and Propagation, vol. 52, no. 1, pp. 315-318, Jan 2004. DOI: 10.1109/TAP.2003.822448.

[16] E. A. Theodorou, M. R. Gorman, P. R. Rigg, and F. N. Kong, "Broadband pulse-optimised antenna," Microwaves, Optics and Antennas, IEE Proceedings $H$, vol. 128, no. 3, pp. 124-130, June 1981. DOI: 10.1049/ip-h-1.1981.0020.

[17] R. T. Lee and G. S. Smith, "A design study for the basic tem horn antenna," IEEE Antennas and Propagation Magazine, vol. 46, no. 1, pp. 86-92, Feb 2004. DOI: 10.1109/MAP.2004.1296150.

[18] D. Baker and C. V. D. Neut, "A compact, broadband, balanced transmission line antenna derived from double-ridged waveguide," in 1982 Antennas and Propagation Society International Symposium, vol. 20 May 1982, pp. 568-571. DOI: 10.1109/APS.1982.1 148767.

[19] H. Amjadi and F. T. Hamedani, "A novel 2-18ghz tem doubleridged horn antenna for wideband applications," in Proceedings of 2011 Cross Strait Quad-Regional Radio Science and Wireless Technology Conference, vol. 1, July 2011, pp. 341-344. DOI: 10.1109/CSQRWC.2011.6036954.

[20] J. Shao, G. Fang, J. Fan, Y. Ji, and H. Yin, "Tem horn antenna loaded with absorbing material for gpr applications," IEEE Antennas and Wireless Propagation Letters, vol. 13, pp. 523-527, 2014. DOI: 10.1109/LAWP.2014.2311436.

[21] M. Kanda, "The effects of resistive loading of "tem" horns," IEEE Transactions on Electromagnetic Compatibility, vol. EMC-24, no. 2, pp. 245-255, May 1982. DOI: 10.1109/TEMC.1982.304025.

[22] K. L. Shlager, G. S. Smith, and J. G. Maloney, "Tem horn antenna for pulse radiation: an optimized design," in IEEE Antennas and Propagation Society International Symposium. 1995 Digest, vol. 1, June 1995, pp. 228-231. DOI: 10.1109/APS.1995.530002.

[23] C. A. Grosvenor, R. T. Johnk, D. R. Novotny, N. Canales, B. Davis, and J. Veneman, "TEM horn antenna design principles," Tech. Rep., 2007.
[24] H. Choi and S. Lee, "Design of an exponentiallytapered tem horn antenna for the wide broadband communication," Microwave and $\mathrm{OP}$ tical Technology Letters, vol. 40, no. 6, pp. 531-534, Mar 2004. DOI: 10.1002/mop.20025.

[25] M. Khorshidi and M. Kamyab, "New exponential tem horn antenna with binomial impedance taper," International Journal of Electronics and Communications, vol. 64, no. 11, pp. 1073-1077, Nov 2010. DOI: 10.1016/j.aeue.2009.10.002.

[26] H. D. O. Ascama, R. Hiramatsu, A. M. Oliveira, C. P. Dionisio, and S.T.Kofuji, "Simulation and manufacturing of a miniaturized exponential uwb tem horn antenna for uwb radar applications," Journal of Microwaves, Optoelectronics and Electromagnetic Applications, vol. 12, no. 2, pp. 655-665, Dec 2013. DOI: 10.1590/S217910742013000200033

[27] L. Song and Y. Nie, "An ultra-wide band exponential flared tem horn antenna for impulse radar systems," in IET International Radar Conference 2015, Oct 2015, pp. 1-2. DOI: 10.1049/cp.2015.1173.

[28] J. G. Malherbe and N. Barnes, "Tem horn antenna with an elliptic profile," Microwave and Optical Technology Letters, vol. 49, no. 7, pp. 1548-1551, Apr 2007. DOI: 10.1002/mop.22488.

[29] ANSYS, "HFSS - High Frequency Structure Simulator." [Online]. Available: https://www.ansys.com/products/electronics/ansys-hfss

[30] R. E. Collin, Foundations for microwave engineering. John Wiley \& Sons, 2007.

[31] J. A. J. RIBEIRO, Engenharia de antenas: fundamentos, projetos $e$ aplicações. São Paulo: Érica, 2012.

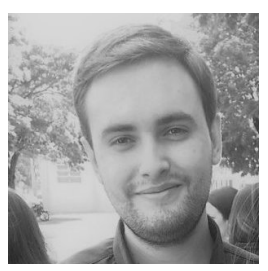

Evandro Cesar Vilas Boas was born in Conceição das Pedras, Minas Gerais, Brazil, in 1993. He received the B.Sc. degrees in telecommunication engineering from the National Institute of Telecomuncation (Inatel), Santa Rita do Sapucaí, Minas Gerais, Brazil, in 2016. He is currently a researcher in WOCA (Wireless and Optical Convergent Access) Laboratory, National Institute of Telecommunications (Instituto Nacional de Telecomunicações - Inatel). He also has been working at the Inatel Competence Center (ICC-Inatel) with R\&D radio frequency (RF) projects since 2017. His research interest are center upon antennas, radio frequency and propagation.

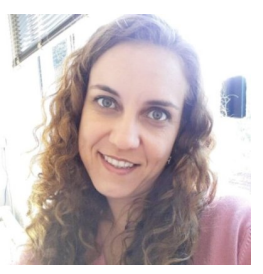

Jéssica Abranches Pinto Ribeiro was born in Pedregulho, São Paulo, Brazil, in 1981. She received the B.Sc. degrees in electrical engineering from the National Institute of Telecommunication (Instituto Nacional de Telecomunicações - Inatel), Santa Rita do Sapucaí, Minas Gerais, Brazil, in 2016. She is currently a M.Sc. student in telecommunications engineering at Inatel. Her research areas include: devices for communication systems, RF circuits, antennas and waves propagation.

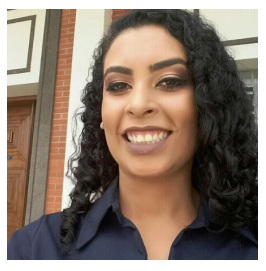

Karine de Lourdes Mateus da Costa was born in Santa Rita do Sapucaí, Minas Gerais, Brazil, in 1991. She received the B.Sc. degrees in telecommunication engineering from the National Institute of Telecommunication (Instituto Nacional de Telecomunicações - Inatel), Santa Rita do Sapucaí, Minas Gerais, Brazil, in 2016. She is currently a M.Sc. student in telecommunications engineering and a researcher in the ICT Lab (Information and Communication Technologies Laboratory) at Inatel. Her research line is: satellite-terrestrial communications in 5G systems and Software Defined Network (SDN) and Network Function Virtualization (NFV) technologies. 


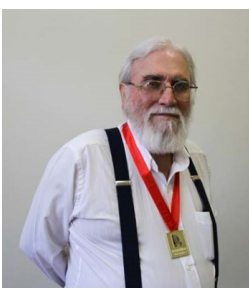

José Antônio Justino Ribeiro is currently a professor in Federal University of Itajubá (Unifei) and in National Institute of Telecommunications (Inatel). $\mathrm{He}$ received the bachelor degrees in Electrical and Telecommunications Engineering from Inatel, and a Doctor of Science and Master degrees, both in Electronic Engineering, from Technological Institute of Aeronautics (ITA), in São José dos Campos SP. For several years he has worked in teaching and research activities in the fields of electromagnetics, antennas, microwaves and optical communications, in both undergraduate an graduate courses of electrical engineering. He is the author or co-author of many papers in conference and technical journals and is the author of four books in Portuguese published by Editora Erica/Saraiva: Optical Communications, Electromagnetic Waves Propagation, Microwave Engineering and Antenna Engineering.

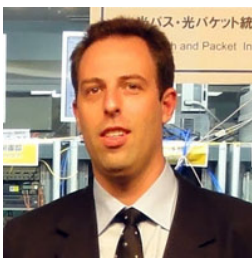

Antônio Marcos Alberti is the head of the ICT $\mathrm{Lab}$ and an associate professor and researcher at the Instituto Nacional de Telecomunicações, INATEL, Brazil, since 2004. In 2012, Antônio was a visiting researcher at Future Internet Department of ETRI, in South Korea. He received the M.Sc. and Ph.D. degrees in Electrical Engineering from Campinas State University (Unicamp), Campinas, SP, Brazil, in 1998 and 2003, respectively. Since 2008, he is designing and implementing a future Internet architecture called NovaGenesis.

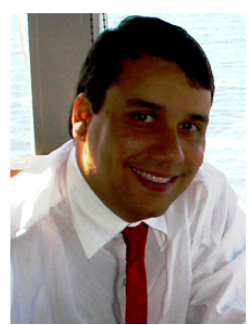

Arismar Cerqueira Sodré Jr. received his B.Sc. Degree in Electrical Engineering from the Federal University of Bahia-Brazil in 2001, M.Sc. Degree from Unicamp-Brazil in 2002 and Ph.D. degree from Scuola Superiore SantAnna-Italy in 2006. He was Invited Researcher and Professor from many world-recognized universities, such as University of Oulu (2017), Scuola Superiore SantAnna-Italy (2015 and 2017), Danish Technical University-Denmark (2013), Max-Planck Institute-Germany (2010) and University of Bath-UK (2004, 2005 and 2007). He was Associate Professor from the State University of Campinas (Unicamp) from March 2009 to August 2011, when he joined the National Institute of Telecommunications (Inatel) from Brazil to work in the same position. Since 2009 he has been acting as a Coordinator of R\&D Projects on diverse areas of telecommunications, including Antennas, 5G Networks, Radars and Microwave Photonics. He is a holder of 09 patents, has transferred 17 products to the industry and has published 189 scientific papers. 